\title{
Demarcating Contextualism and Contrastivism
}

DOI:

$10.1017 / \mathrm{S} 0031819121000218$

\section{Document Version}

Accepted author manuscript

Link to publication record in Manchester Research Explorer

\section{Citation for published version (APA):}

Bebb, J. (2021). Demarcating Contextualism and Contrastivism. Philosophy, 1-27. https://doi.org/10.1017/S0031819121000218

\section{Published in:}

Philosophy

\section{Citing this paper}

Please note that where the full-text provided on Manchester Research Explorer is the Author Accepted Manuscript or Proof version this may differ from the final Published version. If citing, it is advised that you check and use the publisher's definitive version.

\section{General rights}

Copyright and moral rights for the publications made accessible in the Research Explorer are retained by the authors and/or other copyright owners and it is a condition of accessing publications that users recognise and abide by the legal requirements associated with these rights.

\section{Takedown policy}

If you believe that this document breaches copyright please refer to the University of Manchester's Takedown Procedures [http://man.ac.uk/04Y6Bo] or contact uml.scholarlycommunications@manchester.ac.uk providing relevant details, so we can investigate your claim.

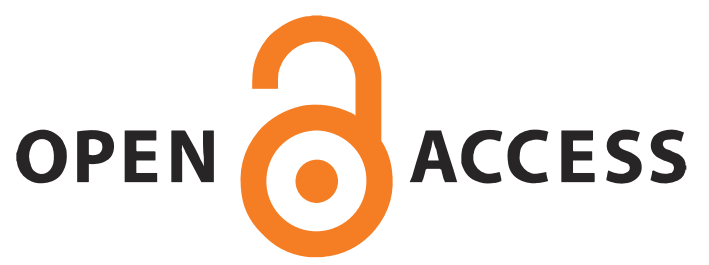




\title{
Demarcating Contextualism and Contrastivism
}

\begin{abstract}
In this paper I argue that there is a significant but often overlooked metaphysical distinction to be made between contextualism and contrastivism. The orthodox view is that contrastivism is merely a form of contextualism. This is a mistake. The contextualist view is incompatible with certain naturalist claims about the metaphysical nature of concepts within whichever domain is being investigated, while the contrastivist view is compatible with these claims. So, choosing one view over the other will involve choosing to affirm or deny a significant metaphysical claim. As such, a demarcation ought to be put in place between contextualism and contrastivism.
\end{abstract}

\section{$\underline{\text { Introduction }}$}

There is a great deal of confusion regarding the relationship between two major approaches to conceptual analysis in philosophy - contextualism and contrastivism - with the latter regularly and, I contend, inaccurately demoted to being a mere variant of the former. More specifically, contrastivist accounts are regularly viewed as proposing the same core claims as any contextualist account that appeals to a notion of contextually relevant alternatives. This paper aims to set the record straight and demonstrate that contrastivism should be understood as a distinct approach, one that results in significantly different metaphysical consequences to those that are entailed by contextualism.

A distinction between these two approaches was initially defended by Jonathan Schaffer in his 2004 paper 'From Contextualism to Contrastivism'. In the paper, Schaffer presents his correspondence with Lewis, who argues for a contextualist view about knowledge that appeals to relevant alternatives and quips that:

The only thing we disagree about is whether we disagree. (Schaffer, 2004, p. 
This scepticism towards the contextualist/contrastivist distinction was shared by Neta, who described Schaffer's account as:

... one of the most explicit, comprehensive, and thoroughly defended contextualist theories of knowledge to date. (Schaffer, 2004, p. 97)

Despite this resistance, in his 2004 paper Schaffer perseveres with the distinction, outlining three alleged differences between his contrastivist account and the accounts proposed by the contextualists. He concludes that, while the two views are 'sibling theories', contrastivism provides a 'more suitable ... model [of the context dependence of knowledge statements], which preserves the core contextualist insights while resolving the main objections to contextualism' (2004, p. 97). From this, it is clear that in 2004, Schaffer saw contrastivism as a position that was distinct from and superior to the kind of contextualist account advanced by Lewis and his ilk, despite there being some shared elements between the two views.

Yet in his more recent works on the topic, we can see that Schaffer has abandoned this commitment to the distinction between contextualism and contrastivism. His 2012 coauthored paper with Knobe now refers to a more developed version of his 2004 account of knowledge as a 'form of contextualism' (Schaffer \& Knobe, 2012, p. 676). We see a similar dialling back in Schaffer's work on causation. In 2005's 'Contrastive Causation', we are presented with an explicitly contrastivist account of causation, with little mention being made of contextualism¹. But by 2013's 'Causal Contextualism', the same contrastivist account is explicitly presented as being a kind of contextualism.

\footnotetext{
${ }^{1}$ Contextualism is, in fact, only mentioned twice. The first is when Schaffer notes that the framework provided by his contrastive account of causation is 'roughly analogous to that of epistemic contextualism' (Schaffer, 2005, p. 315) because they both integrate 'relevant alternatives into the relation' (ibid). Here Schaffer is referring to epistemic contextualist accounts like Lewis's, where the contextual salience of different epistemic possibilities will affect whether or not a given knowledge claim is true. The fact that Schaffer considers these views as analogous suggests that he recognises there are some similarities between the two views. However, he also states that epistemic contrastivism would make for a better analogy with causal contrastivism, which clearly shows that he still maintains a distinction between contextualism and contrastivism. The second time that contextualism is mentioned in this paper is in an endnote where he states that the causal contextualist claim that 'cause' is context-sensitive is more well supported than the epistemic contextualist claim that 'knows' is context-sensitive. He does not say any more than this, so it is unclear from this what he takes the relationship between contextualism and contrastivism to be.
} 
This move by Schaffer away from his 2004 view was, I suggest, a mistake - one which has not been identified as such, including by Schaffer himself. There is a metaphysically significant difference between the kind of contextualism that Lewis argues for and the contrastivism that Schaffer argues for, and so it is a mistake to try and paint contrastivism as a mere brand of contextualism. Put simply, the difference is that the contextualist view is incompatible with certain naturalist claims about the metaphysical nature of the referent of the relevant concept, while the contrastivist view is compatible with these claims. This difference in compatibility with the naturalist claims is significant because it fundamentally affects our motivations for choosing one position over the other. Those who wish to uphold these naturalist claims will have a good reason to prefer a contrastivist account over a contextualist account. So, by understanding and accepting that contrastivism is a distinct approach from contextualism, we can achieve a new understanding of what we are buying into when we decide to endorse one approach over the other.

The goal of this paper will be to demonstrate the existence of this difference between contextualism and contrastivism, and to argue that a demarcation should be made between the two approaches. I will proceed as follows. In Section 1 I provide a brief overview of the contextualist approaches to various different areas of philosophy and identify a core set of commitments that are common to all these approaches, but which have largely been left unclear in previous literature. Particular attention will be paid to the contextualist accounts that rely on a notion of relevant alternatives. In Section 2 I provide the same overview for contrastivism. In Section 3 I will begin to explain how these two views differ by drawing on the three differences that Schaffer provided in his 2004 paper, arguing that Schaffer's distinctions do not do quite capture the metaphysically significant difference between contextualism and contrastivism. Finally, in Section 4 , I develop my positive account of the distinction and demonstrate that there is an important metaphysical difference between the two views.

\section{The Core of Contextualism}

In the literature, 'contextualism' denotes a particular kind of approach towards understanding a given concept, according to which the truth of statements involving terms that express the target concept are context-sensitive. What is meant by 'context-sensitive' 
here is that these statements could, in one context, express a proposition that is true, and in a different context they could express a proposition that is false. The concepts that this approach has been applied to are both numerous and varied. To give a non-exhaustive list, there are contextualist accounts of knowledge, causation (Menzies, 2004a) (Menzies, 2004b) (Menzies, 2007) (Menzies, 2009), modality (Kratzer, 1977), quantifiers (Westerståhl, 1989) (Stanley \& Gendler Szabó, 2000), gradable adjectives (Kennedy, 2007), morality (MacFarlane, 2007)2 , vague expressions (Kamp, 1981), and many more.

Contextualists generally limit their focus to a single concept, and so are only interested in demonstrating that statements containing terms that are an expression of the target concept are context-sensitive. To give some examples of this: contextualists about knowledge argue that statements containing the term 'knows' are context-sensitive; contextualists about morality do the same with statements containing terms like 'ought', 'good', or 'virtue'; contextualists about gradable adjectives focus on terms like 'tall', 'smooth', or 'hot'; and for contextualists about modality, it's terms like 'possible' and 'necessary'. These are terms that are importantly related to the target concept and are used to predicate something about the subject(s) of a statement. I will henceforth be referring to such terms as 'c-terms'. The contextualist about concept $x$ is thus attempting to argue that statements containing c-terms that express $x$ are context-sensitive in virtue of the fact that they contain c-terms that express $x$.

There are many different ways of cashing out this claim that c-term statements are contextsensitive. For my purposes, I only need to focus on those accounts that are likely to be viewed as examples of both contextualism and contrastivism. Specifically, these are accounts where the context-sensitivity of statements containing c-terms is explained by appeal to the contextual relevance of possible alternatives to one or more of those statements' subjects. To clarify this, let's examine two contextualist accounts from two distinct domains: knowledge and causation.

\footnotetext{
${ }^{2}$ One thing to note here is that MacFarlane's accounts of knowledge and morality are often labelled as being 'relativist' rather than 'contextualist'. In this paper I will refrain from providing any commentary on the relationship between relativism and contextualism. Instead, I will simply observe that MacFarlane's accounts both meet the definition of contextualism provided at the start of this section, and so for that reason I will consider these to be contextualist accounts.
} 
First, knowledge. Contextualists about knowledge include Lewis (1996), DeRose (1992) (1995) (1999), Cohen (1988) (1998) (1999), Heller (1999), and Neta (2003a) (2003b). What all these theorists have in common is their endorsement of the claim that statements containing the c-term 'knows' are context-sensitive. In other words, they hold that a statement of the form 'S knows that $\mathrm{p}$ ' can express a true proposition in one context and a false proposition in a different context.

Lewis's contextualist analysis of knowledge is a paradigm example of a contextualist account that appeals to a notion of relevant alternatives. On his account, 'S knows that $\mathrm{p}$ ' is true only if $S$ can use the evidence available to them in order to rule out all relevant alternatives to $p$ (Lewis, 1996, pp. 551-553). To illustrate this, consider the following statement:

1) Moore knows that he has hands ${ }^{3}$.

The traditional invariantist view of statements such as these is that they express the same proposition with the same truth-value in all contexts. Contextualists usually respond by stating that (1) expresses something true when uttered in an everyday context, but in the context of an epistemology seminar, for example - where the bar for what counts as knowledge is much higher and sceptical scenarios are taken more seriously - it expresses something false.

On Lewis's contextualist account, (1) is true only if Moore can eliminate all relevant alternatives where he does not have hands. Alternatives include possibilities such as Moore's having stumps instead of hands and Moore's being a brain in a vat. The relevance of an alternative is determined by contextual factors. In an everyday context, the more straightforward alternatives like Moore's having stumps will be relevant, while the more extreme alternatives, like his being a brain in a vat, will not be relevant. So, in this everyday context, Moore only needs to eliminate the possibility that he has stumps for (1) to be true. Since Moore can clearly see that he does not have stumps, this possibility is eliminated by the evidence. The possibility that he is a brain in a vat cannot be eliminated through the use of perceptual evidence, but this has no effect on the truth-value of (1) because this alternative is not contextually relevant. However, it is a relevant alternative in the context of the epistemology seminar. As a result, the fact that this alternative cannot be eliminated by

\footnotetext{
${ }^{3}$ Example from (Schaffer, 2004, p. 73).
} 
the available evidence renders (1) false in this context. So, on Lewis's account, whether or not a given knowledge statement expresses something true will (at least partly) depend on which alternatives are relevant in the context of utterance.

Contextualist accounts that appeal to a notion of contextually relevant alternatives are not just limited to the domain of knowledge. Second then, let's consider the contextualist account of causation offered by Peter Menzies (2007) (2009), who argues that the truthvalues of causal statements are relative to contextual orderings of possible worlds based on normality (2007, pp. 826-828). Put simply, the truth or falsity of a given causal statement will depend on what we consider to be the 'normal state' of the causal system that we are interested in, as this will be the relevant counterfactual scenario/alternative state that we appeal to when evaluating a given causal claim. A cause is understood as the event(s) that makes the difference between the system being in its normal state and its actual state.

To illustrate, imagine a lightning strike occurs in the middle of a forest, leading to a devastating forest fire ${ }^{4}$. The forest fire is counterfactually dependent on the lightning strike, but it is also counterfactually dependent on the presence of oxygen in the atmosphere. Assuming a counterfactual account of causation, we are provided with two candidate causes, each expressible as one of the following causal statements:

2) The lightning strike caused the forest fire.

3) The presence of oxygen caused the forest fire.

A group of forest rangers are attempting to figure out what caused this fire in order to prevent future fires. In this context, (2) seems intuitively acceptable, while (3) seems intuitively unacceptable. So, the lightning strike gets to count as having caused the forest fire and the presence of oxygen is relegated to being a mere condition for the occurrence of the fire.

Now consider a second context of assessment, where a group of Venusians observe both the lightning strike and the subsequent forest fire from space ${ }^{5}$. Lightning strikes do in fact occur on Venus, and for the purposes of the example we can suppose that they are far more common than on Earth. Another important feature of Venus is that it has no oxygen in its

\footnotetext{
${ }^{4}$ The version of the example presented here is given by Schaffer $(2013$, p. 42).

${ }^{5}$ Inspired by (Putnam, 1982, p. 150).
} 
atmosphere, and consequently no fires occur on its surface. So, the Venusians will be surprised at the sight of the forest fire and will want to know how it happened, since all previously observed (by them) lightning strikes produced no such thing. In this context, an utterance of (3) seems to be far more acceptable than it was in the context of the forest rangers, and (2) seems to be far less acceptable.

Contextualists like Menzies argue that their account best explains the apparent difference in the intuitive acceptability of causal statements that we find in cases like this. (2) is acceptable in the context of the forest rangers and unacceptable in the context of the Venusians because it is true in the former and false in the latter. Likewise, (3) is true in the context of the Venusians and false in the context of the forest rangers. On Menzies' account $^{6}$, these differences in the truth-values of (2) and (3) are a result of the fact that in different contexts, a different alternative state of the causal system is relevant. In the context of the forest rangers, the normal/relevant alternative state is one where oxygen is present, but there is no lightning strike and consequently no forest fire. Here, the lightning strike makes the difference between the relevant alternative state of the system and the actual state of the system, while the presence of oxygen does not. So, in this context, (2) is true and (3) is false. Yet in the context of the Venusians, the normal/relevant alternative state of the system is one where there is a lightning strike but no oxygen, resulting in no forest fire. Here the presence of oxygen does make the difference between the relevant alternative state of the system and the actual state of the system, while the lightning strike does not. Consequently, in this context, (3) is true and (2) is false. From this it should be clear that, on Menzies' account, the truth or falsity of any given causal statement will depend on contextually relevant alternative states of the causal system in question, with the relevant states being those that are the most normal.

The lesson to take from this section is that all contextualists agree on one thing: that whether or not a statement containing a c-term expresses something true will always be context-sensitive. This context-sensitivity can be explained in many different ways, with one being that it is the result of whether or not non-actual alternatives to the subject of those cterm statements are, in the context, relevant alternatives. Contrastivism also invokes

\footnotetext{
${ }^{6}$ Menzies himself discusses a structurally isomorphic case in (Menzies, 2007, pp. 209-211).
} 
alternatives to explain the context-sensitivity of certain c-term statements. As a result of this, contrastivist accounts are often mistakenly labelled as contextualist. Before examining where the error lies, we first need to be clear on how contrastivist accounts themselves make use of alternatives in their analyses.

\section{The Core of Contrastivism}

I will begin by examining the ways in which contrastivism is uncontroversially similar to contextualism. The most apparent point of similarity is that contrastivism is also largely used as a way of analysing the c-term statements of a target concept that involves a kind of context-sensitivity. As with contextualism, this approach has been applied to a wide range of concepts, including knowledge (Schaffer, 2004) (Schaffer \& Knobe, 2012), causation (Hitchcock, 1996a) (Schaffer, 2005) (Schaffer, 2013) (Northcott, 2008) (Maslen, 2004), explanation (van Fraassen, 1980) (Garfinkel, 1981) (Lipton, 1990) (Hitchcock, 1996b), grounding (Schaffer, 2016), obligation (Snedegar, 2017), moral luck (Driver, 2015), and more. The contrastivist's main claim is that the c-term statements we typically use are context-sensitive. Specifically, they are sensitive to the different alternatives that may or may not be contextually salient. With this in mind, it becomes easy to see how the likes of Lewis and Neta might assume that contrastivism is merely a form of contextualism that appeals to relevant alternatives.

What makes a contrastivist approach distinct from the relevant-alternatives contextualist accounts we have looked at so far is the explanation that they give for this contextsensitivity. An important feature ${ }^{7}$ of this explanation is the claim that c-term statements have one or more extra argument places that are typically hidden or suppressed (Schaffer, 2004, p. 87) (Schaffer, 2005, p. 308) (Blaauw, 2013, p. 90). This means that the kinds of cterm statements we use most often are, when taken on their own, semantically incomplete. That is, when considered outside of a context, these statements do not express a complete proposition, and only do so when used within a context. So, the context completes the

\footnotetext{
${ }^{7}$ As pointed out by an anonymous referee, there are some examples of theorists providing accounts that are widely recognised as contrastivist and that do not have this feature. Notable examples of this include SinnottArmstrong's work on contrastivism, as well as the account presented in Menzies' 'Platitudes and Counterexamples (2009). For the sake of simplicity, I will avoid discussion of these accounts until Section 4, where I will address their existence as a potential objection to my analysis.
} 
proposition, and different contexts will complete the proposition in different ways, producing different propositions. Thus, the relevant c-term statements are contextsensitive.

This then raises the question: what exactly is it that context supplies to complete these propositions; what fills in these hidden argument places? The contrastivist's eponymous answer is that the argument places are filled in with a set of contrasts. This means that a completed c-term proposition will express a multi-part relation that holds between the statement's original referents and this contrast set. The members of this contrast set will be a contextually salient set of possible alternatives to the referents of the c-term statement in question. Therefore, the proposition that is expressed by a typical c-term statement will be partly determined by which possible alternatives are salient within that statement's context of utterance.

To help make it clear what this all means, it will be useful to examine a specific contrastivist account. I will focus primarily on Schaffer's (2004, pp. 101-112) (2008, pp. 235-245) contrastivist account of knowledge to allow for comparison with Lewis's account from the previous section. On Schaffer's account, binary knowledge statements of the form 'S knows that $p^{\prime}$ are semantically incomplete and contain a hidden argument place that is to be filled by a salient alternative to $p$. Schaffer refers to this as the mechanism of 'ternicity', as it means that all knowledge relations are three-place relations. A complete knowledge statement expresses a ternary relation between a subject, a proposition, and a contrast to that proposition. A statement expressing such a relation will be of the form 'S knows that $p$ rather than $\mathrm{p}^{* \prime}$, where ' $\mathrm{p}^{* \prime}$ stands for at least one contextually salient alternative proposition to p. Statements like this are acceptable for English speakers to use. However, people typically stick to the incomplete versions of the statements, and so those are the statements that the contrastivist focuses on.

Let's return to statement (1). Since this is a binary knowledge statement, the contrastivist claims that it has a hidden argument place that needs to be filled by a set of contextually salient alternatives to the proposition <Moore has hands>. In an everyday context, the alternatives we would consider salient are close possible alternatives like <Moore has stumps>, while distant alternatives like <Moore is a brain in a vat> would not be salient. So, 
an utterance of (1) in an everyday context will, according to the contrastivist, express something like the following proposition:

$1 \sim$ ) $<$ Moore knows that he has hands rather than stumps $>.^{8}$

For this to be true, it must be the case that Moore is able to rule out the possibility that he has stumps. Fortunately, he is able to do this, as he can look and see that he has hands and not stumps.

Things are different in the context of a philosophy seminar, where the alternative <Moore is a brain in a vat> is salient. Therefore, an utterance of (1) in this context will express something like:

$1 \#)<$ Moore knows that he has hands rather than that he is a brain in a vat $>$.

This is false because Moore is unable to rule out the possibility that he is a brain in a vat using the evidence available to him.

Here we can see how someone might conclude that contrastivism is merely a form of contextualism. Schaffer's account fits in perfectly with the contextualist accounts discussed in the previous section as he argues for the context-sensitivity of a set of c-term statements that is cashed out in terms of the contextual relevance of alternatives. This is equally true of other contrastivist accounts. It therefore seems entirely reasonable to conclude that contrastivism is merely a brand of contextualism that is extremely similar to (or even identical with) the kind of contextualist accounts that appeal to relevant alternatives.

I believe that this conclusion is mistaken, as there is an important point of difference that can be easily overlooked: contrastivists are committed to the view that the relations they are interested in have relata that are not specified by typical c-term statements about those relations. However, those relata can be specified by c-term statements (( $\left.1^{\sim}\right)$ and $(1 \#)$ are examples of how this can be done), and this entails that there are (at least in principle) complete c-term statements with no role for context to play. For example, 'Holmes knows that Mary stole the bicycle rather than the wagon' (Schaffer, 2004, p. 78) is an acceptable

\footnotetext{
${ }^{8}$ Of course, there may be more alternatives that are salient in an everyday context and will consequently be a part of the contrast set. However, for the sake of readability, the examples I provide in this paper will only contain a single alternative.
} 
statement in English that explicitly specifies a contrast. On Schaffer's account, this statement is semantically complete: there are no empty argument places to be filled in by the context. Consequently, this statement, along with many others like it, is not contextsensitive ${ }^{9}$.

The fact that contrastivism allows for statements like these that cannot be context-sensitive will be important for distinguishing between contextualism and contrastivism in Section 4 . In the next section I will lay the groundwork for making that distinction by examining Schaffer's attempt to do the same. Ultimately, I will argue that his account misses the mark by failing to offer a substantial difference between the two approaches, even though it does point us in the right direction.

\section{Schaffer's Points of Difference}

The picture that has emerged from the discussion so far is that contrastivism is strikingly similar to the contextualist accounts that appeal to relevant alternatives. Indeed, the two positions are so similar that one could be forgiven for thinking they are identical. The only notable difference is that the contrastivist argues that certain c-term statements contain a hidden argument place that is typically filled in by the context of utterance. On its own this does not provide us with a solid foundation for demarcating contextualism and contrastivism, as those who maintain that the latter is just a version of the former might argue that this difference only amounts to a minor linguistic point. However, this would be a mistake. The linguistic difference signposts a metaphysically significant distinction in the commitments each approach has towards certain naturalistic claims.

\footnotetext{
${ }^{9}$ It may be argued that the contextualist could attempt a similar move to eliminate the context-sensitivity from a given c-term statement by specifying the contextual features that the statement is sensitive to within the statement itself. For example, we could rewrite (1) to say, 'Moore knows that he has hands relative to the standards of assessment $S_{1}{ }^{\prime}$, where $S_{1}$ is a placeholder for the standards that are in place in a specific context. This statement will be invariant because we no longer have to appeal to the context to find out what standards we should be assessing the knowledge claim against. However, this is not analogous to the move made in the contrastivist case because this statement is not a completed version of (1). This would only be the case if the contextualist were to claim that (1) has a hidden, empty argument place that needed to be filled by a set of standards. As things stand, the contextualist does not make this claim, and so this statement refers to a different relation than the one referred to by (1). Likewise, the contextualist would also have to hold that the relation that is referred to by $\left(1^{\sim}\right)$ and $(1 \#)$ is different to the relation that is referred to by (1). To argue otherwise would be to endorse a theory that is not contextualism.
} 
In this section, I will begin to spell out this distinction by returning to Schaffer's 2004 paper, where he outlines three points of difference between his contrastivist account of knowledge and the corresponding contextualist accounts. What I will demonstrate is that, although these points of difference are a useful step in the right direction, when taken on their own they merely highlight a linguistic difference between the two positions without providing the kind of metaphysically significant distinction we need to ground a demarcation between contextualism and contrastivism. In Section 4, I will provide such a distinction.

Schaffer's three points of difference between contextualism and contrastivism about knowledge are as follows:

i) They employ distinct linguistic models for generating context-dependent truthconditions of knowledge statements.

ii) They have distinct linguistic mechanisms for factoring alternatives into the truth conditions of knowledge statements.

iii) They offer distinct philosophical accounts of how ordinary knowledge is shielded from sceptical doubt. (Schaffer, 2004, p. 82)

We can immediately rule out difference (iii) as a means of providing a general distinction between contextualism and contrastivism, as it only applies within the domain of knowledge. The points of difference identified by (i) and (ii) are more promising, although they ultimately do not get at the heart of the distinction. Let's examine each in turn to identify why they fail to do this.

In his discussion of (i), Schaffer distinguishes between the models of 'indexicality' and 'ternicity' (2004, pp. 82-87). On the model of indexicality, the context-dependence of knowledge statements results from the fact that the same statement can express different propositions in different contexts. As an analogy, a statement containing an indexical like ' $\mathrm{I}$ ' (e.g. 'I am in Paris') will express many different propositions with different truth-values depending on who uses it in a given context. On the model of ternicity, 'contextdependence is generated by the absence of an explicit setting for $\left[\left\{p^{*}\right\}\right]$, which is then implicitly saturated by different alternatives in different contexts' (Schaffer, 2004, p. 82). In other words, the context-sensitivity in contrastivism comes from there being an argument place that can be filled in a number of different ways depending on the context. So, while 
both models allow for the possibility that a single statement can express different propositions in different contexts, they differ in how this is achieved. On indexicality the same statement can express entirely different propositions in different contexts, while on ternicity, the only thing that will shift will be the contrast(s) referred to by the completed proposition.

A reason that immediately presents itself for why (i) cannot be used to ground a general demarcation between contextualism and contrastivism is that while many contextualist accounts do employ this model of indexicality, it is not true that all contextualist accounts employ this model ${ }^{10}$. This is shown by the fact that we can distinguish between indexical and non-indexical forms of contextualism ${ }^{11}$ (MacFarlane, 2009, pp. 231-250). On this distinction, indexical forms of contextualism will, unsurprisingly, use the model of indexicality to account for the context-sensitivity of the truth-conditions of c-term statements. So, on this form of contextualism the context-sensitivity of c-term statements is modelled as being a result of different propositions being expressed in different contexts.

Non-indexical forms of contextualism differ in that they model the context-sensitivity of cterm statements as resulting from the same proposition being judged by contextually varying standards. That is, the same statement will express the same proposition in all contexts. Any difference in the truth-values of those statements across different contexts is the result of that proposition being evaluated according to different standards across those different contexts. This model is distinct from the indexicalist model, but the account is still contextualist because the claim being made is that the c-term statements of our target concept are all context-sensitive: they can express a true proposition in one context and an (identical) false proposition in another. What this means for our inquiry is that (i) cannot be used as a point of difference between contextualism and contrastivism, because, to put it bluntly, non-indexical contextualism exists ${ }^{12}$.

\footnotetext{
${ }^{10}$ It is also not always made clear which model is being used in any given contextualist account.

${ }^{11}$ As noted by an anonymous reviewer, this distinction may not be exhaustive. However, the fact that it can even be made, clearly suggests that there are forms of contextualism that do not employ the model of indexicality.

${ }^{12}$ It is unsurprising that Schaffer doesn't recognise this since much of the discussion of this distinction occurred in the years after he presented (i) as a point of difference between contextualism and contrastivism.
} 
Let's now turn to point (ii). Here Schaffer distinguishes between two different linguistic mechanisms for factoring alternatives into the truth conditions of knowledge statements: 'relevance' and 'saturation' (Schaffer, 2004, pp. 87-90). The kind of alternatives that Schaffer is talking about here are the non-actual propositions that, if contextually salient, will make up the contrast set for a completed knowledge claim. The mechanism of saturation consists in those alternatives being used to fill in the empty argument place of an incomplete, binary knowledge statement. That is, the mechanism takes us from 'S knows that $p^{\prime}$ to ' $S$ knows that $p$ rather than $\left\{p^{*}\right\}^{\prime}$. So, on this mechanism, alternatives are factored into the truth conditions of knowledge statements by filling in the gaps of binary knowledge statements. In ternary knowledge statements, this mechanism is not needed since there are no empty argument places.

Schaffer distinguishes this mechanism of saturation from the mechanism of relevance. On the mechanism of relevance, 'alternatives enter into the truth-conditions via the semantical rule of relevant alternatives (as triggered by the 'knows' indexical)' (Schaffer, 2004, p. 87). There are two points regarding this mechanism that undermine its ability to be used as a distinguishing feature of contextualism. The first, is that not every contextualist account argues that the relevance of alternatives matter for the truth-values of knowledge statements. For instance, MacFarlane's contextualist account of knowledge holds that the truth-values of knowledge statements are sensitive to the relevance of epistemic standards and not alternatives (2009, pp. 236-237). The reason that Schaffer chooses to focus on alternatives here is, I believe, that he is looking to distinguish his contrastivist account from contextualist accounts like Lewis's, where the truth-values of knowledge statements are sensitive to the contextual relevance of alternatives. Recall that on Lewis's account, someone can only be truly said to know that $p$ if they are able to rule out all and only the relevant alternatives to $\mathrm{p}$. So, alternatives are only factored into the truth-conditions of knowledge statements if they are relevant, making this an example of the mechanism of relevance. However, despite this, the fact that there are contextualist accounts that do not employ this mechanism makes this a poor choice to motivate a general demarcation between contextualism and contrastivism.

The second point concerns how this mechanism actually functions, and specifically relates to Schaffer's use of the term 'indexical' when he states that the mechanism is 'triggered by the 
"knows" indexical' (Schaffer, 2004, p. 87). As discussed earlier, the use of 'indexical' here is inappropriate because there are non-indexical versions of contextualism, and the mechanism seems to function differently depending on which kind of contextualist account is being offered. On the indexical account, different alternatives are factored in by the term 'knows' being used to mean different things in different contexts. To illustrate, we can use an indexicalist version of Lewis's account. In the everyday context $\left(C_{E}\right),(1)$ expresses a proposition containing the '...knows- $\mathrm{C}_{\mathrm{E} . . .}$ ' relation, which can only obtain if Moore can eliminate relevant alternatives, like his having stumps. The relation that (1) refers to in the context of the epistemology seminar $\left(C_{s}\right)$, '...knows- $C_{s . . . '}$, is much less likely to obtain because it relies on Moore also being able to eliminate the alternative that he is a brain in a vat. I will leave it open as to whether or not these two relations, '...knows- $\mathrm{C}_{\mathrm{E} . . .}$ ' and '...knows-C...' are two forms of the same relation or two completely distinct relations. Either way, it amounts to the same thing, which is that, on the indexicalist account, alternatives are incorporated into the truth-conditions of knowledge statements by being relevant to whether or not the relation picked out by the term 'knows' actually obtains.

Things are slightly different on the non-indexicalist account. On this account the relation that is picked out by 'knows' will always be the exact same relation, but it is characterised broadly enough that whether or not it obtains depends on specific features of the context. On a non-indexicalist version of Lewis's account, the relation referred to by 'knows' will be something like '...believes that... and can rule out all the alternatives that are relevant in the context of utterance'. So, this knowledge relation will obtain if the contextually relevant alternatives have been eliminated. In an everyday context, only alternatives like Moore's having stumps are relevant. Since this alternative can be ruled out, the relation will obtain in this context, and (1) will be true. Yet in the context of a philosophy seminar, alternatives like Moore being a brain in a vat become relevant. Since this alternative cannot be ruled out, the relation does not obtain and (1) is false. So, as with the indexicalist account, alternatives are incorporated into the truth-conditions of knowledge statements by being relevant to whether or not the relation picked out by the term 'knows' actually obtains. The difference for the non-indexicalist is that 'knows' will always pick out the same specific relation. What we can conclude from this is that the indexical and non-indexical views use very similar mechanisms for factoring alternatives into the truth-values of knowledge statements, and 
that this mechanism differs significantly from the one used by the contrastivist for the same end.

This point of difference is a more promising line of inquiry, particularly when taken in conjunction with the first point. However, all that has really been demonstrated so far is that contextualism and contrastivism use different linguistic mechanisms to achieve the same end of having the contextual relevance/salience of alternatives affect the truth-values of knowledge statements. There is definitely a point to be made here, as it seems like there is a very real difference between an account that characterises knowledge statements as making claims about contextually-sensitive relations and an account that characterises knowledge as a three-place relation where one of those places is usually filled in by the context. Yet this difference does not seem metaphysically significant enough to motivate a demarcation between contextualism and contrastivism. In the next section, however, I demonstrate that there is a metaphysically significant difference between these two views that goes beyond a minor difference in linguistic mechanisms.

\section{Distinguishing Between Contextualism and Contrastivism}

As my distinction between contextualism and contrastivism is a metaphysical one, its significance will be best understood within a metaphysical domain. For this reason, I will first examine how it applies in the domain of causation.

When it comes to causation, the distinction between contextualism and contrastivism is, I argue, rooted in whether or not either position is compatible with the view that causation is a 'natural relation', in a sense to be explained. Contrastivism is compatible with that view, while contextualism is incompatible with that view. As a result, these two positions place very different constraints on what we can say about the metaphysical nature of causation.

To proceed, I will first explain the view that causation is a natural relation. The view that I have in mind here is also discussed by Menzies in his 'Platitudes and Counterexamples' (2009). There he states that 'natural relations are external relations such as temporal and spatial distance that play an important role in the scientific conception of reality' $(2009, \mathrm{p}$. 342). He attributes the view that causation is a natural relation to Peter Strawson, who says that 'causality is a natural relation which holds in the natural world between particular 
events or circumstances, just as the relation of temporal succession does or that of spatial proximity' (1992, p. 109).

Menzies then goes on to describe how Strawson distinguishes this natural relation of causation from the non-natural relation of explanation, which Strawson characterises as 'an intellectual or rational or intensional relation' that 'does not hold between things in the natural world, things to which we can assign places and times in nature' but instead 'holds between facts or truths' (ibid). So, to claim that causation is a natural relation is to claim that causal relations hold in the natural world: they are 'out there' in the world and are the kinds of things that we uncover through empirical investigation. Whether or not these relations obtain will depend entirely on how things are in the natural world within the vicinity of their relata. The obtaining of such relations will be completely unaffected by 'nonnatural' factors such as our epistemic state, the aims of our enquiry, the interests of the speaker, societal norms, and so on.

To further clarify this notion of a natural relation, it may help to distinguish this sense of 'natural' from another sense that is frequently used by the likes of Lewis (1983). This other sense is used by Lewis to refer to properties/relations, whose patterns of instantiation constitute the structure of reality. On this understanding, entities that share the same natural property will be genuinely similar in some respect. Some examples of natural properties in Lewis's sense might include having a mass of $5 \mathrm{~kg}$ or being positively charged. Entities that share a more 'artificial', non-natural property need not have anything in common beyond satisfying the same predicate. Disjunctive properties - such as the property of having-a-5kg-mass-or-a-positive-charge - are a paradigm example of nonnatural properties on Lewis's sense. However, in the sense of 'natural' used by both Menzies and I, the property of having-a-5kg-mass-or-a-positive-charge can be considered natural because the matter of whether or not it is instantiated in a particular object depends on features of the object itself (whether the object has a mass of $5 \mathrm{~kg}$ or is positively charged), and not on things such as our interests and epistemic states and so on.

I argue that what distinguishes causal contextualism from causal contrastivism (as well as causal invariantism) is that the former is incompatible with the view that causation is a natural relation. My argument for this claim begins by noting that if causation really is a natural relation, any statement of 'c caused e' would be a claim about the existence of some 
relation that holds in the natural world. Whether or not that relation obtains would depend on what is going on out there in the world in the vicinity of $c$ and $e$, and not on non-natural factors such as conversational context. So, if causation is a natural relation, then the obtaining of that relation cannot depend on context. Since the obtaining of such a relation is the thing that makes 'c caused e' true, we would have to conclude that the truth-values of causal statements are not context-sensitive. This directly contradicts the core claim of contextualism about causation.

In response to this, it might be tempting to argue that it is entirely consistent for a contextualist about causation to hold that causation is a natural relation, since some context-sensitive statements do in fact exclusively refer to things that are natural. Consider the statement, 'I am six feet tall'13. The truth-value of this statement is context-sensitive because it can be true when uttered by one person and false when uttered by another. Yet what this sentence describes is entirely natural. The referent of ' $I$ ' will be determined by a natural feature of the world: the fact of who actually used the word. Whether or not that person is six feet tall is also a matter that will be also be determined by facts about the natural world, or more specifically, by facts about that person's height. So, holding that the truth-values of a statement are context-sensitive does not entail that the statement has to be referring to something non-natural.

However, this response does not pose a threat to my claim that contextualism about causation is incompatible with the view that causation is a natural relation, because it relies on the unjustified assumption that the contextualist argues for a kind of context-sensitivity that is analogous to the context-sensitivity we find in statements containing an indexical. The thing is, the specific claim that the contextualist endorses is not just that there are statements that are context-sensitive, but that there are statements that are contextsensitive in virtue of containing a c-term. This kind of context-sensitivity is different to the kind of context-sensitivity found in statements that are context-sensitive in virtue of containing an indexical, because c-terms and indexicals are distinct kinds of terms: the former are predicative expressions, and the latter are referring expressions. So, for the above response to be a valid counterargument to my view, there needs to be an additional

\footnotetext{
${ }^{13}$ Thank you to an anonymous referee for this example.
} 
premise stating that the context-sensitivity of an indexical statement is analogous to the context-sensitivity of a c-term statement.

I reject this premise on the grounds that the context-sensitivity found in indexical statements differs significantly from the context-sensitivity found in c-term statements. With indexical statements, the context-sensitivity of the statement arises from the fact that the referent of the indexical can vary across different contexts. In the case of 'I am six feet tall', it can in principle be used to refer to anyone, with the actual referent only being fixed by the context of utterance. When it comes to c-term statements, their context-sensitivity is a result of context determining whether or not the relation referred to by the c-term actually obtains. After all, c-terms are predicative expressions: they assert that something is true of some object(s). That is, they assert that a given thing has a certain property or stands in a certain relation. So, the context-sensitivity found in statements containing a c-term must be an effect of context determining whether or not the objects referred to by the statement actually have the property/stand in the relation that the c-term refers to. Thus, in the case of 'c caused e', context is not fixing which (natural) relation in the world is being referred to ${ }^{14}$; instead, it is fixing whether or not there is a causal relation between c and e. With this distinction in place, statements that are context-sensitive in virtue of containing an indexical can no longer function as counterexamples to my analysis, since the contextualist is concerned with a different kind of context-sensitivity: one that statements have in virtue of containing a c-term.

\footnotetext{
${ }^{14}$ It could be argued that this is contradicted by Schaffer's remark that on the contextualist model of indexicality 'what is variable [across different contexts] is the relation denoted by "knows"' (2004, p. 83). However, this ignores the fact that what I have argued here is compatible with the view that 'knows' refers to different relations in different contexts. The claim here would be that the 'knows' in 's knows that p' could, in one context, refer to the relation of knowledge 1 , and then in another context refer to knowledge2. The context-sensitivity of 's knows that $p$ ' could then be explained by the relation of knowledge ${ }_{1}$ obtaining in the former context, while knowledge ${ }_{2}$ does not obtain in the latter context. Yet it would still be true that the context-sensitivity of this knowledge statement is a result of context determining whether or not the relation referred to by 'knows' obtains, it is just doing so by determining which relation is expressed by each use of 'knows'. This is distinct from the kind of context-sensitivity found in statements containing an indexical, as there the context determines which thing the indexical refers to, and the truth-value of the statements depends on whether or not the statement's predicate is true of that thing. So, with statements containing an indexical, the context-sensitivity comes from the context determining which object the predicate is alleged to be true of, while the context-sensitivity of c-term statements comes from the context determining whether or not the predicate really is true of the object that the statement refers to (and in the case of relational predicates, this will come down to whether or not the relation actually obtains).
} 
It is this kind of context-sensitivity that is incompatible with the view that causation is a natural relation. If causation is a natural relation, then its obtaining in any given case is not something that will be in any way determined by non-natural factors, including conversational context. The implication for 'c caused e' is that context will not in any way affect whether or not a causal relation holds between $\mathrm{c}$ and e. This is significant because there being a causal relation that holds between $\mathrm{c}$ and $\mathrm{e}$ is both sufficient and necessary for the truth of 'c caused e'. So, if context has no effect on whether or not a given causal relation will obtain, then it will also have no effect on whether or not a causal statement asserting the obtaining of such a relation is true. More generally, this means that context plays no role in determining whether or not any given causal statement is true, contrary to what the causal contextualist argues for. Therefore, causal contextualism is incompatible with the view that causation is a natural relation.

To be sure, none of this is to say that the contextualist about causation is committed to the view that there is no natural relation that holds between cause and effect. Indeed, it seems likely that there is some natural relation that links these events (e.g. counterfactual dependence). However, on a contextualist account, this cannot be a relation of causation, because causation is not a natural relation.

Contextualism about causation is therefore incompatible with the claim that the claim that causation is a natural relation. A clear illustration of this point can be seen from the fact that Menzies, a self-proclaimed contextualist, refers to this claim as a 'philosopher's myth' (2009, p. 355). This has also meant that those who have sought to uphold the view that causation is a natural relation have often found themselves drawn towards invariantism.

There is, however, another option available if we wish to uphold the view that causation is a natural relation: contrastivism. As I indicated earlier, contrastivism, unlike contextualism, is compatible with the view that causation is a natural relation. The reason for this is connected to the conclusion of the previous section: that the two approaches utilise different linguistic mechanisms to achieve the same end of having the contextual relevance/salience of alternatives affect the truth-values of causal statements. For the contextualists, these alternatives are not considered to be part of a semantically complete version of the statement. 
Consider the contrastivist account of causation that is offered by Schaffer (2005) (2013). Here causation is characterised as a four-place relation that holds between a cause, an effect, a causal contrast (a contrast set of alternatives to the cause), and an effectual contrast (a contrast set of alternatives to the effect). This means that an utterance of ' $c$ caused $e^{\prime}$ expresses something like 'c rather than c* caused e rather than $\mathrm{e}^{* \prime}$, where $c^{*}$ stands for the causal contrast and $\mathrm{e}^{*}$ stands for the effectual contrast. As with all contrastivist accounts, these contrasts are usually supplied by the context the statement is used in, but they do not have to be. If we were to simply use a complete, quaternary causal statement, then the context of use is no longer needed to complete the proposition. An example of such a statement would be:

6) The lightning strike rather than the absence of a lightning strike caused the forest fire rather than the absence of a forest fire.

This statement will express the same proposition with the same truth-value regardless of the context where it is used, since there are no hidden argument places that need to be filled by that context. The same holds true for the other statement that we may want to make about this case:

7) The presence of oxygen rather than the absence of oxygen caused the forest fire rather than the absence of a forest fire.

Therefore, unlike contextualism, contrastivism holds that complete causal statements like (6) and (7) are not context-sensitive.

So far, this is just a linguistic point about the behaviour of causal statements on the contrastivist account. However, this point has important implications for the question of whether or not we accept the view that causation is a natural relation. These implications can be brought out when we consider the question of what 'caused' is referring to in (6) and (7). It is entirely consistent and entirely natural for the contrastivist to answer that the thing being referred to is a four-place causal relation that exists out there in the natural world. In other words, it is entirely consistent to say that complete causal statements refer to this four-place relation, and that this four-place relation is a natural relation. It is a relation that is out there in the world for us to discover through empirical investigation, and that obtains 
independently of non-natural factors, including conversational context. Therefore, the contrastivist can accommodate the view that causation is a natural relation, while the contextualist cannot.

Thus, in the domain of causation, contrastivism is metaphysically distinct from contextualism by virtue of being able to accommodate the natural relation view.

Contrastivism also has the benefit of being able to account for many of the problem cases that the contextualist appeals to in order to support their view, as the contrastivist can argue that any influence that contextual factors have on the truth-values of binary causal statements are the result of those statements being completed differently in different contexts through the selection of different contrasts. On this understanding, contrastivism is something of a middle-ground between contextualism and invariantism, albeit one that requires us to abandon the plausible intuition that causation is a two-place relation.

We must now turn to the question of how this demarcation can be applied more generally by considering how it applies in the domain of knowledge. As with causation, contextualism about knowledge involves the denial of a metaphysical claim about knowledge: that knowledge is a relation that is out there in the world and can be studied through empirical investigation. This leads those who support this view to claim that knowledge is a natural kind. What this claim suggests is that knowing is a distinctive psychological state that is directed towards a true proposition. It can therefore be studied empirically in the same way that other psychological states are. This view was first explicitly proposed by Kornblith in $2002^{15}$, but, as Kumar (2014, p. 440) notes, the guiding intuition has also been identified in earlier works from Dretske (1981) and Millikan (1993). Implicitly, the defenders of this view are also committed to the view that knowledge is a natural relation.

This view that knowledge is a natural relation is ruled out by contextualism, as contextualism allows for the possibility that someone could be in the exact same psychological state across two different contexts, whilst only knowing some true proposition in only one of those contexts. Of course, an invariantist account is compatible with the natural relation view, but it does not have the advantage of being able to account for the

\footnotetext{
${ }^{15}$ See (Kornblith, 2002).
} 
intuition that many philosophers have that the truth-values of knowledge statements are affected by the contextual relevance of sceptical scenarios (cf. the discussion of Moore's hands in Section 1). So, absent any form of contrastivism, choosing between contextualism and invariantism in this domain will ultimately come down to whether or not it is worth accepting a solution to the sceptical problem at the cost of denying that knowledge is a natural kind/relation.

Unsurprisingly contrastivism is able to accommodate both of these things by introducing additional argument places into the knowledge relation. In Section 2 we saw how the account handles the sceptical problem by applying it to Moore's hands. It is also compatible with the view that knowledge is a natural relation, as complete knowledge statements can be understood as referring to a natural three-place relation. Therefore, we again have three distinct approaches to analysing the target concept. This gives us another domain where the demarcation between contextualism and contrastivism is metaphysically significant. I see no reason why we could not also apply the demarcation to other domains that permit both contextualist and contrastivist approaches.

At this point, someone might claim that my analysis has failed to distinguish adequately between contrastivism and contextualism, as there are accounts that seem not to conform to my definitions. The demarcation rests on the point that contrastivists are committed to providing analyses of relational concepts, according to which those concepts refer to relations with more relata than we might have expected them to have. Yet there are examples of theorists offering 'contrastivist' accounts that do not make such a claim ${ }^{16}$. As an example, Sinnott-Armstrong provides a contrastive account of knowledge without endorsing the claim that knowledge statements refer to a relation with more than two places (SinnottArmstrong, 2004) (Sinnott-Armstrong, 2006) (Sinnott-Armstrong, 2008). In his 'A Contrastivist Manifesto' he even quotes Schaffer saying that knowledge is a ternary relation (Sinnott-Armstrong, 2008, p. 257) but notably refrains from making the same claim himself. Likewise, Menzies, in his 'Platitudes and Counterexamples', presents his same contextualist account of causation as a 'contrastive' account (2009). Both these authors label themselves as presenting a contrastive account but avoid postulating additional argument places in the

\footnotetext{
${ }^{16}$ Thanks to an anonymous referee for raising this issue.
} 
relations that they talk about. Without any kind of claim about additional argument places, these accounts are more or less identical to the kind of contextualist accounts that appeal to relevant alternatives. Therefore, if we accept that these views are contrastivist, then my analysis has failed to identify a point of difference between contextualism and contrastivism.

I respond by denying that these views are contrastivist - the labelling of them as such by their proponents notwithstanding. When deciding which theories should be included within the umbrella term of 'contrastivism', there is good reason for excluding those that do not involve a claim about additional argument places. If we want to be consistent with how we label our theories, then we really only have two options available to us: one is to follow the understanding I have provided in this paper and the other is to characterise contrastivism broadly enough as to include all of the accounts that are labelled as such. If we take the latter approach then the term 'contrastivism' will simply refer to any view that talks about contextually relevant alternatives, which would include just about every account I have referenced thus far (several of which have never been described as contrastivist). This approach would have the advantage of allowing all the accounts that have been labelled (by others) as contrastive to be properly described as such. However, it would erase the important metaphysical distinction that I have highlighted between the accounts that do and do not claim additional argument places ${ }^{17}$. Therefore, it is far more useful to characterise 'contrastivism' as referring to a view that is distinct from the view referred to by 'contextualism'18.

\footnotetext{
${ }^{17}$ As noted by an anonymous referee, there is the possibility that we could have accounts where c-term statements are understood as having hidden argument places, but where those argument places are not filled by contrasts. If this is correct, then it may be misguided to label such views as 'contrastivist'. However, the existence of such views does not affect my conclusion, as if there were such views, they would certainly not be contextualist.

${ }^{18}$ It may be objected that this response is question-begging because I am using the fact that there is a difference between contextualism and contrastivism to motivate the claim that there is a difference between contextualism and contrastivism. However, that is a misunderstanding of my argument. I have already demonstrated that there is a metaphysically significant difference between the kinds of account that do argue for extra-argument places that are filled in by the context, and those views that do not make this claim. As the boundaries of different views ought to generally respect these differences, it makes sense to label them differently. The labels of 'contextualism' and 'contrastivism' are the most apt for this, given how those terms are already used. The difference that I identify here exists prior to any labelling of views as 'contextualist' or 'contrastivist', so it is not question-begging to then argue that our use of these labels ought to respect this difference.
} 


\section{Conclusion}

I have argued that both contextualism and contrastivism offer different prospects for how to understand the metaphysical natures of our target concepts. Contextualism requires us to deny that the referents of the target concepts are natural. Contrastivism meanwhile, does not come with this requirement. This is a metaphysically significant point of difference between the two positions. To respect this difference, we therefore ought to treat contextualism and contrastivism as entirely distinct approaches to conceptual analysis.

\section{$\underline{\text { References }}$}

Martijn Blaauw, 'Contrastive Belief' in Martijn Blaauw, Contrastivism in Philosophy (London: Routledge, 2013).

Stewart Cohen, 'How to be a Fallibilist', Philosophical Perspectives, 2 (1988), 91-123.

Stewart Cohen, 'Contextualist solutions to epistemological problems: Scepticism, Gettier, and the lottery', Australasian Journal of Philosophy, 76 (1998), 289-306.

Stewart Cohen, 'Contextualism, Skepticism, and the Structure of Reasons', Philosophical Perspectives, 13 (1999), 57-89.

Keith DeRose, 'Contextualism and Knowledge Attributions', Philosophy and Phenomenological Research, 52 (1992), 913-929.

Keith DeRose, 'Solving the Skeptical Problem', The Philosophical Review, 104 (1995), 1-52. Keith DeRose, (1999). 'Contextualism: An Explanation and Defense' in John Greco \& Ernest Sosa, The Blackwell Guide to Epistemology (London: Blackwell, 1999).

Fred Dretske, Knowledge and the Flow of Information (Cambridge MA: MIT Press, 1981). Julia Driver, 'Luck and Fortune in Moral Evaluation' in Martijn Blaauw, Contrastivism in Philosophy (London: Routledge, 2013).

Alan Garfinkel, Forms of Explanation: Rethinking the Questions in Social Theory (London: Yale University Press, 1981). 
Mark Heller, 'The Proper Role for Contextualism in an Anti-Luck Epistemology', Philosophical Perspectives, 13 (1999), 115-129.

Christopher Hitchcock, 'Farewell to Binary Causation', Canadian Journal of Philosophy, 26 (1996a), 267-282.

Christopher Hitchcock, 'The Role of Contrast in Causal and Explanatory Claims', Synthese, 107 (1996b), 395-419.

Hans Kamp, 'The Paradox of the Heap', Journal of Symbolic Logic, 147 (1981), 225-277.

Christopher Kennedy, 'Vagueness and Grammer: The Semantics of Relative and Absolute Gradable Adjectives', Linguistics and Philosophy, 30 (2007), 1-45.

Hilary Kornblith, Knowledge and its place in nature (Oxford: Oxford University Press, 2002).

Angela Kratzer, 'What 'Must' and 'Can' Must and Can Mean', Linguistics and Philosophy, 1 (1977), 337-355.

Victor Kumar, "Knowledge' as a natural kind term', Synthese, 191 (2014), 439-457.

David Lewis, 'New work for a theory of universals', Australasian Journal of Philosophy, 61 (1983), 343-377.

David Lewis, 'Elusive Knowledge', Australasian Journal of Philosophy, 74 (1996), 549-567.

Peter Lipton, 'Contrastive Explanation', Royal Institute of Philosophy Supplements, 27 (1990), 247-266.

John MacFarlane, 'Relativism and Disagreement', Philosophical Studies, 132 (2007), 17-31.

John MacFarlane, 'Nonindexical Contextualism', Synthese, 166 (2009), 231-250.

Cei Maslen, 'Causes, contrasts, and the nontransitivity of causation' in Ned Hall, L. A. Paul, \& John Collins, Causation and Counterfactuals (Cambridge: MIT Press, 2004).

Peter Menzies, 'Difference-making in Context' in Ned Hall, L. A. Paul, \& John Collins, Causation and Counterfactuals (Cambridge: MIT Press, 2004a).

Peter Menzies, 'Causal Models, Token Causation, and Processes', Philosophy of Science, 71 (2004b), 820-832. 
Peter Menzies, 'Causation in Context' in Huw Price \& Richard Corry, Causation, Physics, and the Constitution of Reality: Russell's Republic Revisited (Oxford: Clarendon Press, 2007).

Peter Menzies, 'Platitudes and Counterexamples' in Helen Beebee, Christopher Hitchcock, \& Peter Menzies, The Oxford Handbook of Causation (Oxford: Oxford University Press, 2009).

Ruth Garrett Millikan, White Queen Psychology and Other Essays for Alice (Cambridge MA: MIT Press, 1993).

Ram Neta, 'Contextualism and the Problem of the External World', Philosophy and Phenomenological Research, 66 (2003a), 1-31.

Ram Neta, 'Skepticism, Contextualism, and Semantic Self-Knowledge,' Philosophy and Phenomenological Research, 67 (2003b), 396-411.

Robert Northcott, 'Causation and Contrast Classes', Philosophical Studies: An International Journal for Philosophy, 139 (2008), 111-123.

Hilary Putnam, 'Why There Isn't a Ready-Made World', Synthese, 51 (1982), 141-167.

Jonathan Schaffer, 'From Contextualism to Contrastivism', Philosophical Studies: An International Journal for Philosophy in the Analytic Tradition, 119 (2004), 73-103.

Jonathan Schaffer, 'Contrastive Causation', The Philosophical Review, 114 (2005), 297-328. Jonathan Schaffer, 'The Contrast-sensitivity of Knowledge Ascriptions', Social Epistemology, 22 (2008), 235-245.

Jonathan Schaffer, 'Causal Contextualism' in Martijn Blaauw, Contrastivism in Philosophy (London: Routledge, 2013).

Jonathan Schaffer, 'Grounding in the image of causation', Philosophical Studies, 173 (2016), 49-100.

Jonathan Schaffer \& Joshua Knobe, 'Contrastive Knowledge Surveyed', Noûs, 46 (2012), 675-708. 
Walter Sinnott-Armstrong, 'Classy Pyrrhonism' in Walter Sinnott-Armstrong, Pyrrhonian Skepticism (Oxford: Oxford University Press, 2004).

Walter Sinnott-Armstrong, Moral Skepticisms (Oxford: Oxford University Press, 2006).

Walter Sinnott-Armstrong, 'A Contrastivist Manifesto', Social Epistemology, 22 (2008), 257270.

Justin Snedegar, Contrastive Reasons (Oxford: Oxford University Press, 2017).

Jason Stanley \& Zoltán Gendler Szabó, 'On Quantifier Domain Restriction', Mind and Language, 15 (2000), 219-261.

Peter Strawson, 'Causation and Explanation' in Peter Strawson, Analysis and Metaphysics: An Introduction to Philosophy (Oxford: Oxford University Press, 1992).

Bas van Fraassen, The Scientific Image (Oxford: Oxford University Press, 1980).

Dag Westerståhl, 'Aristotelian Syllogisms and the Generalized Quantifiers', Studia Logica: An International Journal for Symbolic Logic, 48 (1989), 577-585. 